\title{
VAMOS APRENDER TRIGONOMETRIA? UMA EXPERIÊNCIA COM ALUNAS NO ENSINO MÉDIO UTILIZANDO A BALESTILHA
}

\section{LET'S LEARN TRIGONOMETRY? AN EXPERIENCE WITH STUDENTS FROM SECONDARY EDUCATION USING THE BACKSTAFF}

\author{
Antonia Naiara de Sousa Batista ${ }^{1}$ \\ Universidade Estadual do Ceará - UECE \\ Ana Carolina Costa Pereira ${ }^{2}$ \\ Universidade Estadual do Ceará - UECE
}

\begin{abstract}
Resumo
$\mathrm{Na}$ busca por um ensino mais contextualizado e fazendo uso da história da matemática encontramos na Balestilha um recurso metodológico para utilizar nas aulas de matemática. O nosso trabalho tem o objetivo de mostrar que é possível inserir nas aulas de matemática a construção de instrumentos históricos de medida, no nosso caso a Balestilha, para explorar conteúdos matemáticos. Essa experiência foi realizada com cinco alunos da Escola de Ensino Fundamental e Médio José de Alencar, por meio de um curso com duração de 20h/a, ofertado pelo Laboratório de Matemática e Ensino localizado na UECE. Nenhuma delas conhecia a Balestilha e sua relação com a matemática. Cada aluna teve a oportunidade de construir a sua Balestilha, e realizar a aplicação para descobrir a altura de uma parede. Neste sentido, visamos contribuir para uma melhor aprendizagem do aluno/conteúdo/professor por meio de um recurso metodológico ainda pouco conhecido e utilizado em sala de aula, como a Balestilha.
\end{abstract}

Palavras-chave: História da Matemática; Balestilha; Conceitos matemáticos.

\begin{abstract}
Searching for a teaching method more contextualized and making use of the history of mathematics, we found in Backstaff a methodological resource for use in math classes. Our work aims to show that it is possible to introduce in math classes the construction of historical measuring instruments, in this case the Backstaff, to explore mathematical contents. This experiment was carried out with five students of the Elementary and Middle School José de Alencar, through a 20-hour course, offered by the Mathematics and Education Laboratory located at UECE. None of them knew the Backstaff neither its relationship with mathematics. Each student had the opportunity to build their own Backstaff and apply the knowledge to find out the height of a wall. Using this, we aim to contribute to improve students' learning / content / teacher through a methodological resource still barely known or used in the classroom, the Backstaff.
\end{abstract}

\footnotetext{
1 antonianaiarabatista@yahoo.com.br.

2 Carolina.pereira@uece.br.
} 
Keywords: History of Mathematics. Backstaff. Mathematical concepts.

\section{Introdução}

A utilização da História da Matemática como uma tendência pedagógica no ensino básico, vem sendo baste incentivada pelos professores de nível superior. Várias são as disciplinas dentro da graduação voltadas para esse intuito, e que priorizam não só o conhecimento histórico, mas oportunizam ao licenciando descobrir relações entre os fatos históricos e os conceitos matemáticos.

A história da Matemática é encontrada no Ensino Fundamental e Médio muitas vezes nos livros didáticos, como textos suportes antes de iniciar o capítulo sobre determinado conteúdo. Porém, alguns desses textos históricos são de tamanho reduzido e priorizam a história daquele conteúdo especifico, não oferecendo ao professor e ao aluno a oportunidade de perceber a evolução daquele determinado conceito.

No entanto, entendemos aqui o livro didático como suporte para as aulas de matemática e não um livro de história da Matemática completo. Por isso a abordagem e a exploração de fatos históricos que nos proporcione conhecer a evolução de um conceito matemático, está ligado a iniciativa do professor de levar algo além do material didático. Porém, há profissionais que não tem qualquer tipo de preparação para utilizar a História da Matemática em sala de aula. Assim afirma, Baroni, Texeira e Nobre (2004, p. $171-172)$ :

[... o ensino da História da Matemática tem obtido reais avanços no âmbito das universidades, mas ainda são bastante tímidas as iniciativas ou o interesse em levar a História da Matemática a alunos de Ensinos Fundamental ou Médio. Uma das razões poderia ser o fato de que normalmente o professor que ensina História da Matemática em instituições de nível superior não é o mesmo das instituições de ensino básico. E, quando encontramos algum professor secundário ensinando História da Matemática, num viés pedagógico, geralmente é por diletantismo, um trabalho amador, e não porque ele tivesse sido treinado para tal. Embora lentamente, em alguns países isto está mudando. E, para que essa mudança ocorra, é preciso, em primeiro lugar, que os professores dos Ensinos Fundamental e Médio recebam capacitação que os torne aptos a entender sobre a História da Matemática e a conectá-la aos conteúdos trabalhados em sala de aula.]

Outro fator muito ressaltado pelos professores da educação básica na hora de propor uma aula diferenciada, fazendo uso da história da Matemática, é a falta de tempo para pesquisar e planejar uma aula diferente da maneira tradicional. Desta forma, o profissional desperdiça a possibilidade de estar utilizando uma metodologia 
diferenciada em sala para dar suporte as suas aulas, tornando-as mais atrativas e práticas.

No ensino de matemática são diversas as possibilidades de promover aulas diferenciadas do método tradicional, utilizando as tendências pedagógicas como, a etnomatemática, a tecnologia da informação, modelagem, história da matemática, jogos e etc. O uso da história da matemática vem há algum tempo sendo bastante discutida no Brasil, pois, por meio dela é possível entrar em contanto com outras civilizações e culturas matemáticas.

Dentro dela podemos encontrar diversos caminhos a serem estudados, mas um deles são os instrumentos históricos de medida inseridos entre os séculos XVI e XVIII, no qual sua inserção nas aulas de matemática pode surtir um grande efeito no desenvolvimento e na apropriação do conhecimento matemático. Além disso, segundo Oliveira (2010), os artefatos também nos permite entra em contanto com costumes específicos de uma época, e assim, conhecer as práticas exercidas por indivíduos desse período que teriam contribuído para o seu surgimento e desenvolvimento.

No nosso caso trabalhamos mas especificamente, com a Balestilha, um instrumento náutico bastante utilizado nos séculos XVI à XVIII. O uso desse instrumento como um recurso didático oferece a partir do objeto, ou seja, do concreto, a abordagem de conteúdos matemáticos facilitando a aprendizagem do aluno. Desta forma, Lorenzato (2006), ressalta que o intuito do recurso didático nas aulas de matemática é o de promover uma melhor interação entre aluno/conhecimento/professor, buscando desta maneira ajudar o aluno a abstrair determinado conteúdo a partir do uso de diversos materiais concretos, como por exemplo, o material dourado, o ábaco, jogos de tabuleiros e etc.

Dentro dos PCNs, na área das Ciências da Natureza, Matemática e suas Tecnologias, encontra-se uma competência, na qual se encaixa a utilização desse instrumento. A contextualização sócio-cultural motiva o aluno a compreender que todo conhecimento científico e o tecnológico é resultado da influência e da participação ativa do ser humano. A seguir iremos expor dois pontos bastante importante para a área da Matemática como uma Ciência em processo de desenvolvimento constante, encontradas nos PCNs:

Compreender o desenvolvimento histórico da tecnologia associada a campos diversos da Matemática, reconhecendo sua presença e implicações no mundo 
cotidiano, nas relações sociais de cada época, nas transformações e na criação de novas necessidades, nas condições de vida. Por exemplo, ao se perceber a origem do uso dos logaritmos ou das razões trigonométricas como resultado do avanço tecnológico do período das grandes navegações do século 16, pode-se conceber a Matemática como instrumento para a solução de problemas práticos e que se desenvolve para muito além deles, ganhando a dimensão de idéias gerais para novas aplicações fora do contexto que deu origem a elas.

A Balestilha é um instrumento náutico pouco conhecido. Além disso, esse artefato possibilita explorar de maneira melhor a trigonométrica no triângulo retângulo através da sua confecção, ao contrário dos outros instrumentos, como por exemplo, o quadrante, astrolábio, a bússola, que permitem trabalhar com uma trigonometria, mas voltada para o estudo dos ângulos (MOREY E MENDES, 2005).

Segundo (FERNANDES e LONGHINI, 2011) a Balestilha pode ser usada como uma ferramenta didática para abordar conceitos matemáticos e astronômicos, durante a sua construção. Além disso, apresenta que é possível a partir do instrumento confeccionado elaborar atividades para o ensino dos conteúdos citados anteriormente.

Deixando assim, o professor com um papel de facilitador diante do ensino desses conteúdos e oferecendo para os alunos a chance de descobrirem e construírem seu próprio caminho na aprendizagem. O nosso trabalho tem o objetivo de mostrar que é possível inserir nas aulas de matemática a construção de instrumentos históricos de medida, no nosso caso a Balestilha, para explorar conteúdos matemáticos.

\section{O que é a Balestilha?}

A Balestilha é um instrumento náutico muito utilizado entre os séculos XVI e XVIII. De origem desconhecida, pouco se sabe ao certo a data na qual passou a ser utilizada pelos marinheiros em alto-mar. Porém, sua primeira aparição foi constatada no Livro de Marinharia, de João de Lisboa, entretanto o documento não estava datado, mas segundo podemos situá-lo no primeiro quartel do século XVI, não muito posterior a 1514 (ALBUQUERQUE, 1988). Segundo Fontoura (apud Albuquerque, 1988), a Balestilha já era conhecida no século XIV, no entanto, era chamada por diversos nomes, um deles era o Báculo de Jacob, muito utilizado pelos agrimensores medievais para descobrir distâncias de difícil acesso entre dois pontos fixos. Abaixo segue uma figura desse instrumento. 
Figura 01: Báculo de Jacob.

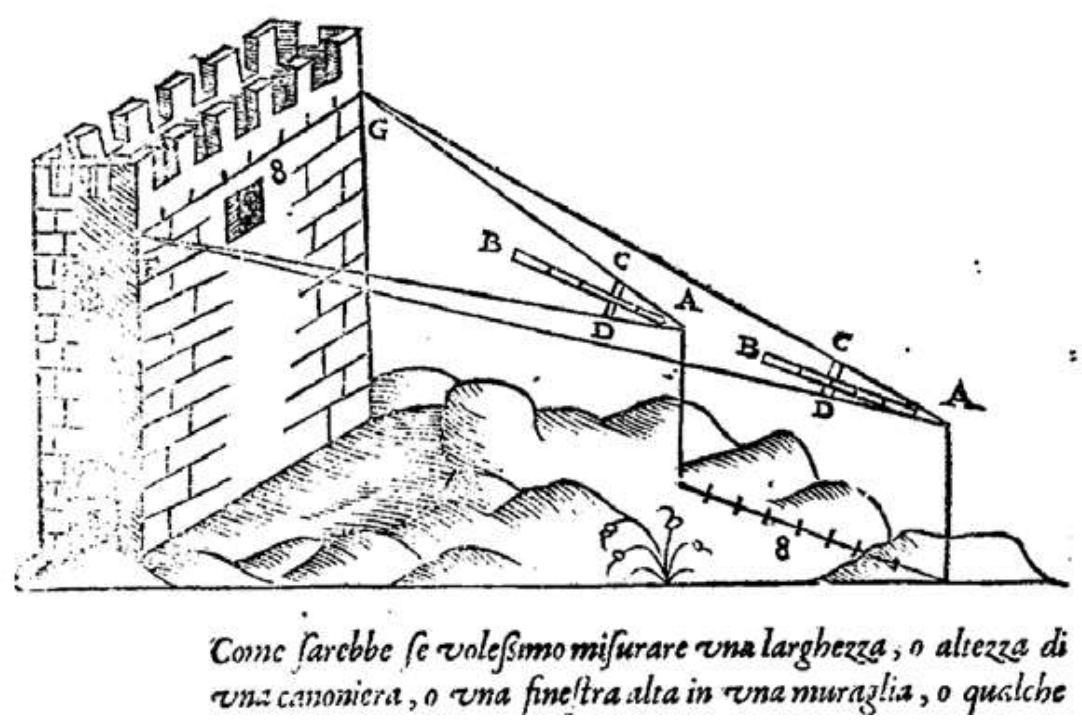

Fonte: Bartoli (1564, p. 11v).

Depois de passar por algumas adaptações em relação aos seus componentes e a sua graduação, o Báculo de Jacob passou a ser usado durante as navegações, após o século XV, agora chamado por Balestilha. A sua função era medir a altura do astro em relação à linha que separa imaginariamente o mar do horizonte, ou a distância entre duas estrelas, todavia essa medida era angular. Logo, essa dupla função the trouxe benefícios em relação a outros instrumentos náuticos existentes no período, como por exemplo, o quadrante, o astrolábio, entre outros, que serviam apenas para medir a distância do astro em relação à linha do horizonte.

Figura 02 - Balestilha do Museu da Marinha em Lisboa.

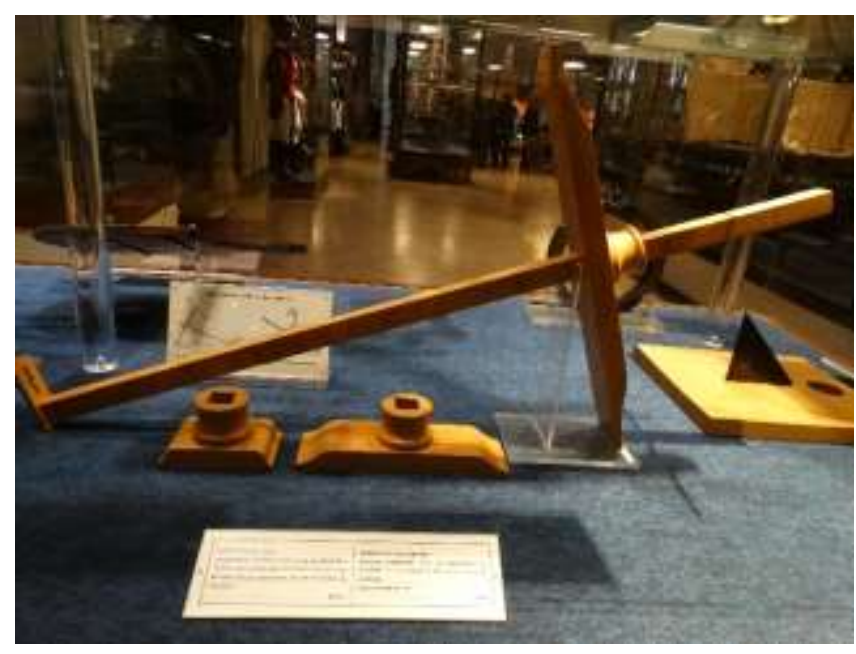

Fonte: Das autoras. 
$\mathrm{O}$ instrumento possui a forma de um "T", os elementos que o compõe são: o virote (vara ou régua de madeira de secção quadrada) e as soalhas (peças de madeira de comprimento menor do que o virote com um orifício no centro que percorrem perpendicularmente). Segundo Pimentel (1762), cada a soalha era construída a partir de uma proporção em relação ao tamanho do virote, a primeira soalha seria $1 / 2$ do virote, a segunda $1 / 4$, a terceira $1 / 8$ e a quarta, também chamada de martinete, seria $1 / 16$ do virote.

Figura 03 - Virote e Soalhas.
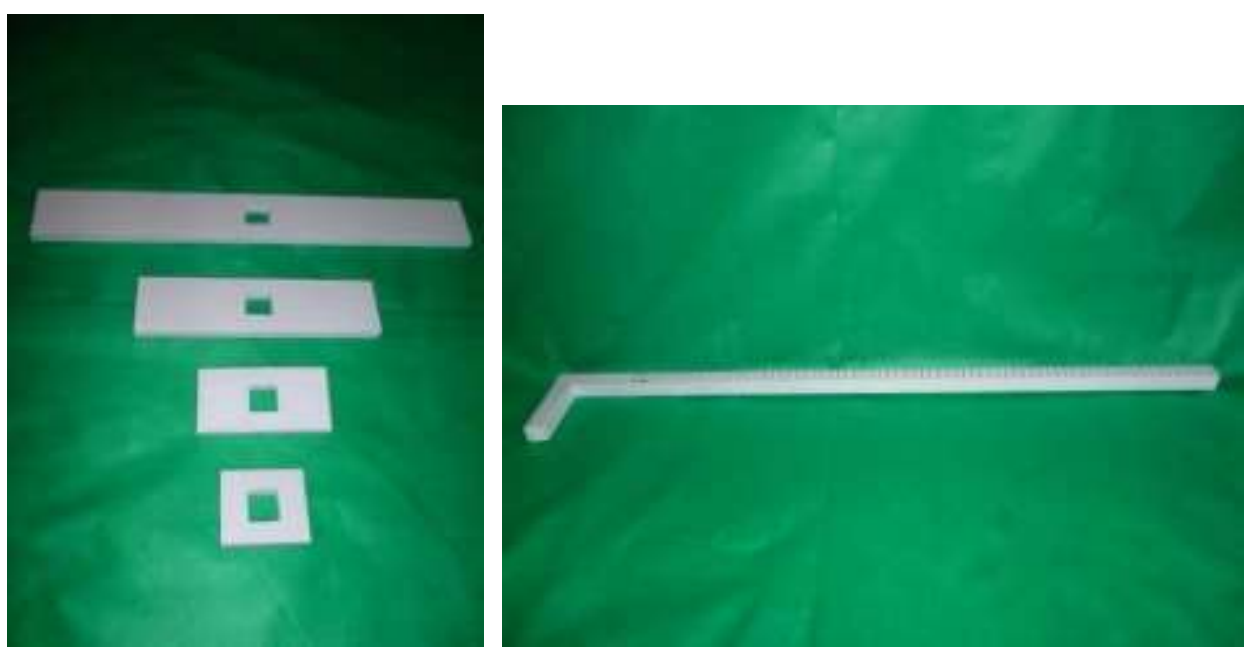

Fonte: Elaborada pelos autores.

No caso das soalhas, cada uma delas vai ser usada para realizar uma graduação especifica no virote. Portanto, a Balestilha só pode conter no máximo quatro soalhas, pois o virote possui apenas quatro faces, onde serão inseridas as graduações posteriormente.

\section{Potencialidades didáticas da Balestilha}

A Balestilha é um instrumento histórico de medida que necessita ser graduado para que posteriormente possa ser utilizado para uma determinada finalidade, no caso dos marinheiros a mesma era utilizada para se obter a localização do navio em alto-mar. A sua graduação pode ser realizada de duas maneiras distintas: de forma geométrica ou trigonométrica.

$\mathrm{Na}$ graduação geométrica, percebemos que durante o processo de execução podemos abordar alguns conteúdos da disciplina de Desenho Geométrico ministrada no 
ensino superior, ou mesmo assuntos relacionados ao Ensino Médio, como por exemplo, conceitos de retas paralelas e perpendiculares, secção de ângulos e medida de ângulos, além de utilizar instrumentos, como o compasso, o esquadro e o transferido para executar a graduação. No nosso caso não usamos está graduação devido o tempo reduzido do curso.

$\mathrm{Na}$ graduação trigonométrica ${ }^{3}$, observamos que é possível durante a efetuação desse recurso, tratar de assuntos relacionados à trigonometria no triângulo retângulo, abordando assim, o conceito de seno, cosseno, tangente e complemento de um ângulo, razões trigonométricas na circunferência e transformações. Além, de podermos abordar outros conceitos matemáticos, como os conceitos de proporção, multiplicação e arredondamento de números decimais.

Depois de confeccionado e graduado o instrumento podemos utilizá-lo não somente para encontrar a distância angular entre duas estrelas, ou o ângulo que separa o astro da linha do horizonte. Fazendo a contextualização da Balestilha podemos usá-la para descobrir a altura de um poste, de uma torre, ou até mesmo de uma parede qualquer, trabalhando assim, com a trigonometria no triângulo retângulo.

\section{Conhecendo nossos interlocutores}

Atualmente, verifica-se um baixo percentual de mulheres matriculadas em cursos superiores nas áreas das ciências exatas nas universidades brasileiras. Esse fenômeno é fruto de um longo processo histórico-cultural no qual parte-se do pressuposto de que meninas não possuem habilidades para carreira na área das ciências exatas. Numa tentativa de minimizar a aguda diferença de gênero existente na educação superior brasileira, o Conselho Nacional de Desenvolvimento Científico e Tecnológico (CAPES), a Petrobrás, a Secretaria de Políticas para as Mulheres e o Ministério da Ciência, Tecnologia e Inovação, em conjunto lançaram uma Chamada Pública para seleção de projetos a serem realizados em parceria com escolas públicas de ensino médio, visando estimular as meninas a procurarem carreiras científicas na área das ciências exatas, engenharias e computação.

O projeto intitulado: "Ariadne: tecendo os fios do conhecimento científico" desenvolveu ações de intervenção junto a Escola de Ensino Fundamental e Médio José

\footnotetext{
${ }^{3}$ Para mais detalhes ver Pereira e Batista (2015).
} 
de Alencar, situada no bairro da Messejana - Fortaleza-CE, um dos mais renomados da capital, sendo também um dos mais pobres, com sua população jovem em situação de vulnerabilidade social. Esse projeto foi destinado às turmas de $2^{\circ}$ ano do ensino médio, cuja professora orientadora é egressa da licenciatura em Física da UECE e trabalha com cinco meninas matriculadas no horário da manhã.

Entre as atividades realizadas do projeto incluem-se preparação para Olimpíada Brasileira de Matemática das Escolas Públicas (OBMEP) e da Olimpíada Brasileira de Astronomia e Astronáutica (OBA), cursos de aprofundamento de conteúdos curriculares de Física e Matemática, visitas a espaços de divulgação científica, elaboração de atividades experimentais para participação na Feira de Ciências da escola, construção de blogs sobre mulheres cientistas, etc.

A expectativa é que a maior proximidade e familiaridade com a área das ciências exatas, fortalecida pelo aprofundamento de alguns conteúdos relacionados aos conhecimentos físicos e matemáticos, estimulem as meninas a procurar por profissões inseridas nessa área.

Em colaboração com essa iniciativa da CAPES, ofertamos um curso para as cinco meninas que faziam parte do projeto "Ariadne: tecendo os fios do conhecimento cientifico" no intuito de atingir um dos objetivos proposto, que seria o de fornecer cursos de aprofundamento de conteúdos curriculares de Física e Matemática.

O título do curso ofertado foi, "O uso de artefatos históricos para a exploração dos conceitos matemáticos: a Balestilha como instrumento de medição”, que tinha como alvo contribuir para melhorar a aprendizagem dos conceitos matemáticos, principalmente relacionados à Trigonometria, e tentar despertar nas discentes o interesse pela área das Ciências Exatas, principalmente em relação a própria matemática.

Durante o curso foram ministradas aulas sobre a história de diversos instrumentos náuticos utilizados entre os séculos XV e XVIII, como por exemplo, o Quadrante, a Tábua da Índia, o Sextante, entre outros, juntamente com a matemática inserida na sua construção e utilização. Posteriormente, relatamos um pouco sobre a história da Balestilha, e em seguida, iniciamos a confecção do instrumento. No curso abordamos apenas a graduação trigonométrica. Por fim, fizemos a aplicação da Balestilha no intuito de descobrir a altura de uma parede. 


\section{Narrando os fatos: o produto de uma formação}

Analisando o material coletado no curso, percebemos que as alunas com faixa etária entre 16 e 17 anos demonstravam interesse pelas disciplinas de matemática, filosofia e sociologia. No início do curso, $60 \%$ das alunas pretendiam cursar faculdade voltada para área das Ciências Humanas, nas seguintes profissões: Biomedicina, Fisioterapia, Música. Relataram que estavam participando do curso, ofertado pela UECE com carga horária de 20h/a, pela oportunidade única de conhecer e aprender de forma diferenciada a matemática vista tradicionalmente nas salas de aulas.

Durante a análise dos questionários diversas vezes ficamos surpresos com o relato das alunas sobre sua vida escolar. Segundo as discentes, os seus professores de matemática do Ensino Fundamental e Médio, nunca utilizaram a história da Matemática como uma tendência pedagógica em sala de aula. Apenas no Ensino Médio se iniciou a introdução de algumas aulas com o uso de data show ou no laboratório de Matemática.

As estudantes comentaram que na maioria das vezes suas dificuldades em relação à aprendizagem Matemática surgem diante do método de explicação adotado pelo professor, que na maioria das vezes transforma conteúdos simples em complexos, como por exemplo, os cálculos em geral e o "jogo de sinais entre números e equações".

Por isso, ressaltaram que por meio da confecção do instrumento é possível apoderar-se dos conteúdos matemáticos inseridos na sua construção de maneira dinâmica, pois quando o aluno fica preso somente a teoria percebe-se um desinteresse pelo conteúdo ministrado naquele momento, enquanto que trabalhando de forma prática e manipulativa, surge uma curiosidade e consequentemente o aluno participa mais da aula.

Figura 04: Aplicação da Balestilha com as alunas do Ensino Médio.

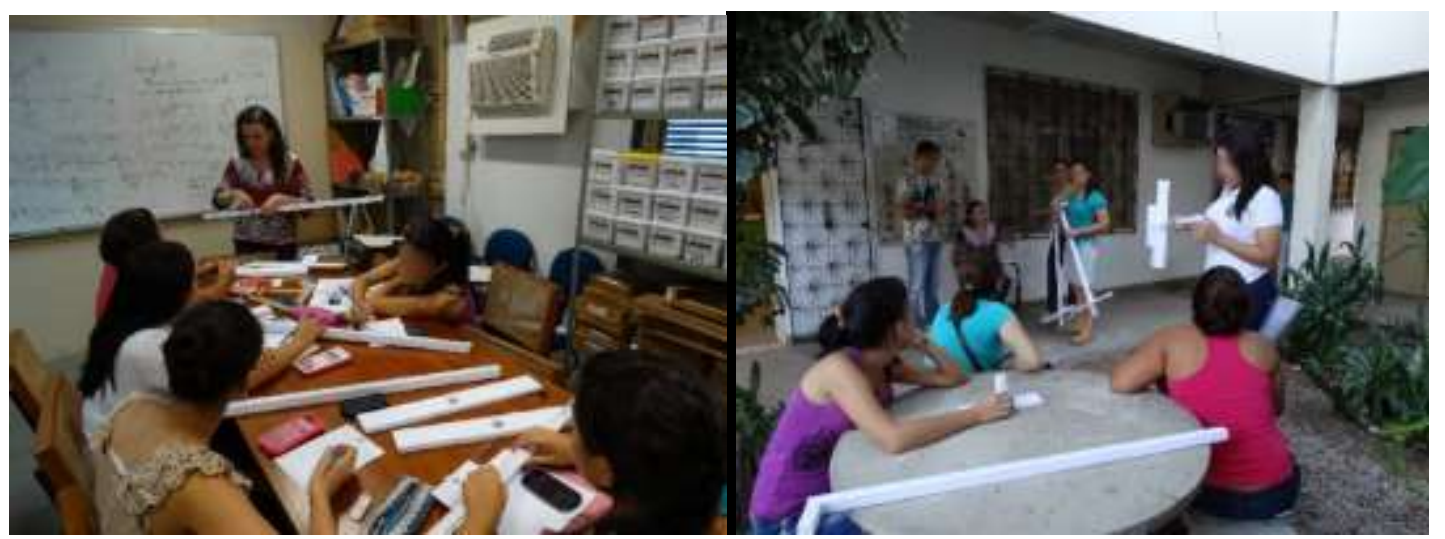

Fonte: Das autoras. 
No final da última aula, as alunas disseram que o curso superou suas expectativas, principalmente em relação a conteúdos matemáticos, como por exemplo, razões trigonométricas na circunferência, que segundo as alunas não tinha compreendido muito bem no $1^{\underline{o}}$ ano do Ensino Médio puderam ver a explicação novamente de maneira mais clara.

A seguir iremos apresentar os conteúdos matemáticos explorados juntos as discentes no momento da graduação trigonométrica: o conceito de seno, cosseno, tangente e complemento de um ângulo; razões trigonométricas na circunferência (principalmente os eixo do seno e do cosseno, os valores de $0^{\circ}, 90^{\circ}, 180^{\circ}$ e $270^{\circ}$ ); transformações (calcular funções trigonométricas da soma $(\mathbf{a}+\mathbf{b})$ e da diferença $(\mathbf{a}-\mathbf{b})$ de dois ângulos a e b); multiplicação de números decimais; arredondamento de números decimais; proporção; expandiu o conhecimento em relação história da Matemática, principalmente sobre os diversos instrumentos náuticos utilizados entre os séculos XVI e XVIII, em especial sobre a Balestilha.

Ao término do curso as discentes concluíram que é possível utilizar a história da Matemática como uma fonte para estudar matemática tanto no Ensino Fundamental quanto no Médio, pois a teoria demonstrada de forma lúdica é bem mais atrativa e fácil de compreender para o aluno. Assim, percebemos que o curso de certa maneira ajudou e incentivou na escolha da sua futura graduação, principalmente estimulando para área das Ciências Exatas, porque diferente do início, $60 \%$ agora do nosso público já estavam mais interessadas nesta área.

\section{Considerações Finais}

Inicialmente, um curso semelhante a este, porém abordando também a graduação geométrica do instrumento, foi ofertado para os discentes em processo de formação no curso de Licenciatura em Matemática da Universidade Estadual do Ceará. No entanto, essa nova experiência realizada com esse grupo de alunas do Ensino Médio, nos proporcionou visualizar uma quantidade maior de conceitos trigonométricos que poderíamos abordar a partir da construção, graduação e aplicação da Balestilha. Tudo isso devido as dúvidas que as meninas tinham no decorre do curso, e por isso, tínhamos sempre que relembrar conteúdos anteriores. 
O curso oportunizou validar o nosso recurso metodológico, pois, sabemos que é essencial para o professor/pesquisador avaliar o uso e a efetividade de sua proposta em sala de aula. Na atualidade sabemos que a maioria dos docentes reclamam muito da falta de tempo para preparar uma aula diferenciada. E também quando se busca por algo que deixe as aulas de matemática mais dinâmicas e atrativa para os nossos alunos, se pensa em primeiro lugar no tempo e material que serão necessários para usar na aplicação. Logo, com esse trabalho temos o propósito de deixar um recurso didático possível de ser utilizado nas aulas de matemática para abordar conceitos trigonométricos, necessitando que o professor se prepare, planeje sua aula e insira ele em suas aulas.

Nesse intuito a nossa pesquisa surgiu com o propósito de ajudar o professor nesta caminhada profissional, tentando encurtar essa distância que há entre o conteúdo e a busca pela sua origem, ou pela necessidade na qual foi criado, ou qual a sua relação com o assunto proposto hoje. Como por exemplo, nesta pesquisa tratamos sobre o uso da Balestilha para abordar conceitos relacionados a trigonométrica, como forma de uma metodologia inovadora que pode ser utilizada antes de iniciar a ministração do conteúdo, ou após.

\section{Referências}

ALBUQUERQUE, Luís de. Instrumentos de Navegação. Lisboa: Comissão Nacional Para As Comemorações dos Descobrimentos Portugueses, 1988. p. 10-29.

BATISTA, Antonia Naiara de Sousa; PEREIRA, Ana Carolina Costa. Ensinando conceitos geométricos e trigonométricos envolvidos na construção e utilização da Balestilha.. In: XI Seminário Nacional de História da Matemática, 2015, Natal/RN. XI Seminário Nacional de História da Matemática, 2015.

BARONI, Rosa Lúcia Sverzut; TEIXEIRA, Marcos Vieira; NOBRE, Sergio Roberto. A investigação científica em história da matemática e suas relações com o programa de pós-graduação em educação matemática. In: BICUDO, Maria Aparecida Viggiani; BORBA, Marcelo de Carvalho. Educação matemática: pesquisa em movimento. São Paulo: Cortez Editora, 2004. p. 164-185.

BARTOLI, C. (1564). Cosimo Bartoli Gentil'huomo, et accademico Fiorentino, Del modo di misurare le distantie, le superficie, i corpi, le piante, le province, le prospettive, $\&$ tutte le altre cose terrene, che possono occorrere agli homini, Secondo le vere regole d'Euclide, \& de gli altri piu lodati scrittori, Venetia, Francesco Franceschi Sanese. 
FERNANDES, Telma Cristina Dias; LONGHINI, Marcos Daniel. A construção de um antigo instrumento para navegação marítima e seu emprego em aulas de astronomia e matemática. Simpósio Nacional de educação em Astronomia, 1., 2011, Rio de janeiro.

LORENZATO, Sergio. Laboratório de ensino de matemática e materiais didáticos manipuláveis. In: LORENZATO, Sergio.Coleção Formação de professores: O Laboratório de Ensino de Matemática na Formação de Professores. São Paulo: Autores Associados, 2006. Cap. 1. p. 3-37.

MOREY, Bernadete; MENDES, Iran Abreu. Conhecimentos matemáticos na época das navegações. Rio Grande do Norte: Sbhmat, 2005. 54 p.

OLIVEIRA, Rosalba Lopes. Artefatos históricos: mediando saberes na formação docente do professor que ensina matemática. In: ENCONTRO NACIONAL DE EDUCAÇÃO MATEMÁTICA, 10., 2010, Salvador. Anais... Salvador: Sociedade Brasileira de História da Matemática, 2010, p. 1-11.

PCN+Ensino Médio: Orientações Educacionais Complementares aos Parâmetros Curriculares Nacionais.

Disponível em: <http://portal.mec.gov.br/seb/arquivos/pdf/CienciasNatureza.pdf>. Acessado em 15 de Junho de 2015.

PIMENTEL, Manuel. Arte de navegar. Lisboa: na Officina de Miguel Manescal da Costa, Impressor do Santo Officio, 1762. 